\title{
Revised-MS-SAA-D-15-01945R1 \\ Human Hemoglobin Structural and Functional Alterations and Heme Degradation upon Interaction with Benzene: A Spectroscopic Study
}

\author{
Reza Hosseinzadeh ${ }^{a, b}$, Ali Akbar Moosavi-Movahedi*a,c \\ a) Institute of Biochemistry \& Biophysics (IBB), University of Tehran, Tehran, Iran \\ b) Medical Laser Research Center, ACECR, Tehran, Iran \\ c) Center of Excellence in Biothermodymanics, University of Tehran, Tehran, Iran
}

* Corresponding author:

A.A. Moosavi-Movahedi, $\mathrm{PhD}$

Institute of Biochemistry and Biophysics (IBB)

University of Tehran

Tehran, Iran

E-mail: moosavi@ut.ac.ir

Tel.: +98 2166403957 ;

Fax: +98216640 4680 . 


\begin{abstract}
Here, the effect of benzene on hemoglobin structure, stability and heme prosthetic group integrity were studied by different methods. These included UV-Vis absorption spectrophotometry, normal and synchronous fluorescence techniques, and differential scanning calorimetry (DSC). Our results indicated that benzene has high hemolytic potential even at low concentrations. The UV-Vis spectroscopic results demonstrated that benzene altered both the globin chain and the heme prosthetic group of hemoglobin increasing met- and deoxy-Hb, while decreasing oxy-Hb. However, with increasing benzene the concentration of all species decreased that is due to heme destruction. The spectrophotometric results show that benzene has a high potential for penetrating to the hydrophobic pocket of hemoglobin. These results were consistent with the molecular docking simulation results of benzene-hHB. Aggregation and thermal denaturation studies show that the increased benzene concentration induced hemoglobin aggregation with a decrease in stability, which is consistent with the DSC results. Conventional fluorescence spectroscopy revealed that the heme degradation species were produced in the presence of benzene. The results of constant wavelength synchronous fluorescence spectroscopy (CWSFS) indicated that at least five heme-degraded species were produced. Together, our results indicated that benzene has adverse effects on hemoglobin structure and function, and heme degradation.
\end{abstract}

Keywords: Hemolysis, Heme destruction, Benzene interaction, Synchronous fluorescence, Hemoglobinemia, Hemoglobin species. 


\section{Introduction}

Hemoglobin constitutes approximately one third of the mass of a mammalian red blood cells. Its major function is to carry oxygen from the lungs through the arteries to the tissues and help to carry carbon dioxide through the veins back to the lungs. The process whereby hemoglobin performs this essential physiological role is characterized by a cooperative interaction among its constituent subunits $[1,2]$. This macromolecule is composed of four chains which are held together through non-covalent interactions [3]. Each chain contains one heme prosthetic group, thus providing four binding sites for oxygen on the hemoglobin. In the alpha chain the 87 th residue is histidine, while in the beta chain the 92nd residue is histidine. A heme group is attached to each of the four histidines in the pocket. Also the heme consists of an organic part containing nitrogen atoms for complexation with the iron atom as a metallic core. The iron atom in the heme binds to the four nitrogens in the center of the protoporphyrin ring [3-5]. The regulated complex structure of hemoglobin is important for oxygen transferring from long to the body and carbon dioxide from body to long. Many factors can impact the normal physiological functions of hemoglobin. Hemoglobin is affected by various endogenous physiological conditions and exogenous agents or environmental pollutants such as drugs, heavy metals, herbicides (alachlor, aminopielik D), paraquat and insecticides (chlorpyrifos and cypermethrin), and organic pollutants [6]. These could have adverse effects on protein structure and function [6]. In addition, the oxidation state of heme iron center is very important for its true action. If the iron is in the ferric state (methemoglobin) the hemoglobin cannot bind to the oxygen molecules and consequently loss common physiological function. Normally, met-hemoglobin levels are $<1 \%$. In oxidative 
stress, hemoglobin act as oxidase resulting in increased level of ferric state hemoglobin and met-hemoglobinemia [7-10]. Hemoglobin lifetime is 120 days due to the limited life span of the RBCs. As the heme is not recycled, degradation of heme is the only way to removing. In most cells, heme degradation is done with heme oxygenase. However, due to the absence of heme oxygenase enzyme in the mature red blood cells and in blood serum, the released heme has to be transported to other body system in order to be degraded by heme oxygenase enzyme. The redox ability of oxy-hemoglobin leads to producing superoxide and hydrogen peroxide reagents which is responsible for nonenzymatic heme degradation. In the other word, these reagents are as initiators in producing various reactive oxygen species that resulted in nonenzymatic heme degradation and heme turnover in red blood cells. Also it should be mentioned that methemoglobin shows catalytic properties, such as peroxidase-like and catalase-like activities, so the redox chemistry of hemoglobin plays an important role in living systems and in specific conditions. Peroxidase activity of hemoglobin make great interest for application in environmental processes, where the metHb system can be used as biocatalyst to remove and oxidation of organic pollutants[11,12]. Various environmental pollutants, hazard materials and toxins can increase oxidative stress in blood. Small chain alkyl benzenes such as BTEX (Benzene, Toluene, Ethylbenzene and Xylene) are a class of toxic, volatile organic compounds. These compounds represent some of the most hazardous materials in gasoline. These chemicals belong to an important class of volatile environmental contaminants and are frequently analyzed in the environment and drinking water. Chronic effects of BTEX include damage to the liver and harmful effects on kidneys, heart, lungs and nervous system. Aromatic hydrocarbons 
have also been associated with the induction of non-immune hemolytic anemia or methemoglobinemia. Currently in the U.S. there are significant concentrations of benzene in ambient air, due in large part to vehicle emissions. Benzene concentration in indoor air is also significant contributors to children's exposure particularly in homes where people smoke [13-16].

Chronic exposure of benzene is associated with various health effects for human. Benzene (water solubility at $15^{\circ} \mathrm{C} \approx 1.8 \mathrm{~g} / \mathrm{L}$ [17]) known as clastogenic and carcinogenic chemical agent that induces primarily hematopoietic cancers in humans[18,19]. The most important blood system disorders can be divided to met-hemoglobinemia, aplastic anemia, pancytopenia, myelodysplasia and acute myeloid leukemia. $1 \mathrm{ppm}$ is the accepted concentration of benzene as exposure standard limit in the USA by OSHA (Occupational Safety and Health Administration) in occupational conditions. However, nowadays, during the progress of the both developing and developed countries the exposure to high levels of benzene is unavoidable[18-21]. Moreover, the toxicity to blood system and carcinogenicity of benzene at or below 1ppm is unclear and an ongoing concern[20,21].

Very limited and few studies are available on BTEX effects on proteins, particularly hemoglobin [22,23], and there are no reports regarding structural effects, stability, heme destruction effects, and heme degradation species produced in interaction of benzene with hemoglobin. In this study, we used spectrophotometric techniques focusing on the effects of benzene on structure, stability, function, aggregation and also effects on heme destruction and hemolysis of red blood cells (RBCs). 


\section{Experimental}

\subsection{Materials}

Benzene, all the buffer salts, and other chemicals were obtained from E. Merck

(Germany). Nitrogen and oxygen gases (99.999\% purity) were from Air Products (UK).

All the solutions were prepared using double distilled water.

\subsubsection{Human adult hemoglobin extraction}

Human hemoglobin was extracted in our laboratory using a previously described method [24]. In brief, new fresh and heparinized blood was centrifuged at $3000 \mathrm{rpm}$ to remove plasma components. The upper yellowish solution was decanted and the packed red cells were washed three times in an isotonic saline solution $(0.9 \% \mathrm{NaCl})$ at a ratio of $1: 10$ for 5 min and subsequently centrifuged at $10000 \mathrm{rpm}$. Red cells were osmetically lysed using cold double distilled water. Membrane components were removed by centrifugation (10000 rpm). The soluble $\mathrm{Hb}$ was centrifuged at high speed (18000 rpm) at least two additional times to remove any insoluble materials. The hemoglobin solution was then brought to $20 \%$ saturation with ammonium sulfate, left standing for 20 min and centrifuged at $20000 \mathrm{rpm}$. The resulting $\mathrm{Hb}$ solution was dialyzed 3 times against $0.2 \mathrm{M}$ phosphate buffer solution ( $\mathrm{pH} 7.4$ ) for $24 \mathrm{~h}$. The purity of the extracted hemoglobin was determined using SDS-PAGE (15\%) and catalase test [25]. 


\subsection{Methods}

\subsubsection{Hemolytic studies}

Blood samples $(6 \mathrm{~mL})$ were collected from healthy and non-smoker volunteers of $\mathrm{HbA}$ genotype in $50 \mathrm{~mL}$ sample tubes containing $1 \mathrm{~mL}$ of ascorbic acid (4\%). The samples were centrifuged at $2000 \mathrm{rpm}$ for $15 \mathrm{~min}$ at $15^{\circ} \mathrm{C}$ to remove plasma and washed with saline buffer solution $(0.9 \% \mathrm{NaCl}$ solution) at ambient temperature. The upper yellowish solution was decanted and the packed red cells were washed again for three times using an isotonic saline buffer solution at a ratio of 1:10 for $5 \mathrm{~min}$ and subsequently centrifuged at $1600 \mathrm{rpm}$ until upper phase color changed from yellow to clear solution. Upper clear solution was removed and the red cells were diluted to $5 \%$ with deionized water at room temperature. The prepared sample $(1.5 \mathrm{~mL})$ was placed in $2 \mathrm{~mL}$ vials and the analyts were added to the vials at desired concentration. The control $(0 \%)$ was considered without any analyt addition, and the control (100\%) was considered by adding triton X100. The vials were incubated at $37^{\circ} \mathrm{C}$ for $45 \mathrm{~min}$ inwater bath. The samples were centrifuged at $1600 \mathrm{rpm}$ and the upper solution was used for lysed hemoglobin concentration determination using a UV-Vis spectrophotometer at $540 \mathrm{~nm}$ [26].

\subsubsection{Aggregation potential studies}

The hemoglobin solution $(50 \mathrm{~mL})$ was prepared $\left(2 \mu \mathrm{mol} . \mathrm{L}^{-1}\right)$, and $1 \mathrm{~mL}$ was placed in a quartz spectrophotometer cell and quickly sealed using parafilm. Various concentrations of benzene were injected in to the cell using a Hamiltonian syringe. To consider the aggregation induction potential of analyts and blank solutions the increasing absorption at $365 \mathrm{~nm}$ at $60^{\circ} \mathrm{C}$ was recorded for 600 seconds. 


\subsubsection{Thermal denaturation and Tm determination}

The hemoglobin solution ( $1 \mathrm{~mL}$ of $2 \mu \mathrm{mol} . \mathrm{L}^{-1}$ ) was placed in a spectrophotometer cell and sealed quickly with parafilm. Appropriate amounts of benzene were injected into the cells and temperature was raised from $25^{\circ} \mathrm{C}$ to $90^{\circ} \mathrm{C}$ at a rate of $1^{\circ} \mathrm{C} / \mathrm{min}$ and the absorption was recorded at $280 \mathrm{~nm}$. Tm was obtained by calculating the midpoint of the spectra.

\subsubsection{Differential Scanning Calorimetry (DSC) measurements}

Differential Scanning Calorimetry studies were carried out using Nano-DSC differential scanning calorimeter (Setaram, France) equipped with a $0.348 \mathrm{~mL}$ cells. The sample cell was filled with hemoglobin and hemoglobin-benzene solutions and the reference cell was filled with a buffer solution that contained all of the sample constituents except the protein. The cells were carefully filled to avoid air bubbles. DSC scans were performed in the temperature range of $20-90{ }^{\circ} \mathrm{C}$. The hemoglobin concentration in all of the experiments was $1 \mathrm{mg} / \mathrm{mL}$. The heating rate was fixed at $1{ }^{\circ} \mathrm{C} / \mathrm{min}$.

\subsubsection{Normal fluorescence measurements of heme degradation species}

Simple fluorescence measurements were carried out using Cary Fluorescence spectrophotometer at $25^{\circ} \mathrm{C}$ and $2 \mu \mathrm{M}$ hemoglobin. Benzene was added to the sample solution and emission fluorescence spectra were recorded at 330-650 nm using $321 \mathrm{~nm}$ as the excitation wavelength and from 450-650 $\mathrm{nm}$ at the excitation wavelength of 460 $\mathrm{nm}$. Excitation and emission slits were fixed at $10 \mathrm{~nm}$ with a scan speed of $5 \mathrm{~nm} / \mathrm{sec}$. 


\subsubsection{Synchronous Fluorescence Spectroscopic Studies}

Synchronous fluorescence spectra of hemoglobin was recorded in a Cary Eclipse spectrofluorometer (Varian Co., Australia) and analyzed to determine the changes around tryptophan and tyrosine residues as a function of benzene concentration for $\mathrm{hHb}$. The synchronous fluorescence spectra were recorded at $25^{\circ} \mathrm{C}$ and $2 \mu \mathrm{M}$ hemoglobin by increasing benzene concentration at intervals of $\Delta \lambda=17 \mathrm{~nm}$ corresponding to tyrosine, and at intervals of $\Delta \lambda=80 \mathrm{~nm}$ corresponding to tryptophan [27,28]. The spectrum was scanned from $250-550 \mathrm{~nm}$ with a scan speed of $1 \mathrm{~nm} / \mathrm{sec}$. Intervals of $\Delta \lambda=17 \mathrm{~nm}$ was also used to determine the new chromophoric heme destruction species produced in the reaction samples due to the effects of benzene on hemoglobin.

\subsubsection{Molecular docking analysis}

MGL tools 1.5.4 with Auto-Grid 4 and Auto-Dock 4 were used to obtain the binding energy, and the binding sites between benzene and human hemoglobin [29]. The crystal structure of hemoglobin was obtained from protein data bank (PDB) (PDB ID: 1HHO). Receptor $(\mathrm{hHb})$ and ligand (benzene) files were prepared using Auto-Dock Tools. The $\mathrm{hHb}$ was enclosed in a box with number of grid points in $\mathrm{x} \times \mathrm{y} \times \mathrm{z}$ directions (126×126×126) and a grid spacing of $0.458 \AA$. Lamarckian genetic algorithms was applied in the docking and 100 genetic algorithm (GA) runs were performed. For each of the docking cases the lowest energy docked conformation, according to the Auto-dock scoring function, was selected as the binding mode. The most favorable docked structure of the protein-ligand complex was viewed and handled with PyMol software [30]. 


\subsubsection{Oxygen Affinity Measurements:}

Two methods were used for measuring oxygen affinity of hemoglobin in the presence of benzene. The first method is Tietz method and is based on spectrophotometric titration of hemoglobin solution with sodium dithionite. This reagent was used for deoxygenation studies of Hbs and measuring oxy and deoxy species in 548 and $577 \mathrm{~nm}$ using UV-Vis spectrophotometry in the absence and presence of benzene $\left(2.8 \times 10^{-8} \mathrm{M}\right)$. The saturation factor was determined based obtained absorbances due to Tietz method [31].

The second method is based on direct measuring of oxygen concentration in sample solutions using electrochemical oxygen clark electrode. The oxygen affinity of $\mathrm{Hb}$ samples was determined via measuring the absorbed oxygen by $\mathrm{Hb}$ molecules. The absorbed oxygen by $\mathrm{Hb}$ samples $\left(\mathrm{O}_{2, \mathrm{Hb}}\right)$ was calculated as below:

$$
\mathrm{O}_{2, \mathrm{Hb}}=\mathrm{O}_{2, \mathrm{PBS}}-\mathrm{O}_{2, \mathrm{PBS}+\mathrm{Hb}}
$$

where, $\mathrm{O}_{2, \mathrm{PBS}}$ and $\mathrm{O}_{2, \mathrm{PBS}+\mathrm{Hb}}$ refer to the amount of oxygen in PBS and in PBS containing $\mathrm{Hb}$, respectively. Prior to measurements the solutions (either PBS or PBS containing $\mathrm{Hb}$ ) were purged with highly pure nitrogen gas for at least $10 \mathrm{~min}$ to remove the dissolved oxygen [22]. Then, the deoxygenated solution in a sealed cell was kept under nitrogen atmosphere throughout the experiments. Thereafter the highly pure oxygen was injected into both solutions under the constant flow rate of $1 \mathrm{~mL} \cdot \mathrm{min}^{-1}$ for a certain time and the amount of $\mathrm{O}_{2, \mathrm{PBS}+\mathrm{Hb}}$ and $\mathrm{O}_{2}$,PBS were determined using oxygen measuring electrode (Oxi 330i, WTW, Germany). The oxygen purging flow rate was also controlled by a volumetric flow meter (Azmoon Motammam, Iran). All experiments were performed at $25^{\circ} \mathrm{C}$. 


\section{Results and discussion}

\subsection{Hemolytic effect of benzene on RBCs}

The study of hemolytic effects of various analyts on RBCs is one of important parts of the studies and scientific reports $[32,33]$. Fig. 1 shows the hemolytic effect of benzene on the RBCs. The RBCs hemolysis effect was increased by increasing benzene concentration. Benzene is a hydrophobic aromatic hydrocarbon and can easily penetrate the cell membrane entering the cell. The penetration into the cell membrane was increased with increasing benzene concentration which can destruct the cell membrane causing hemolysis. It seems that the hemolytic potential of organic compounds depends not only on the hydrophobic character of the amphiphilic organic compound but also on other factors such as volume of hydrophilic part and the chemical structure of the molecule. The increase in permeability of the RBCs membrane due to interaction with benzene and subsequent penetration of benzene in the cell induced colloid osmotic lysis of the cells. However, the symmetric structure of benzene can be lead to decreasing of the hemolytic effect of benzene in comparison with other homologues series in BTEXs (data not shown) $[34,35]$. 


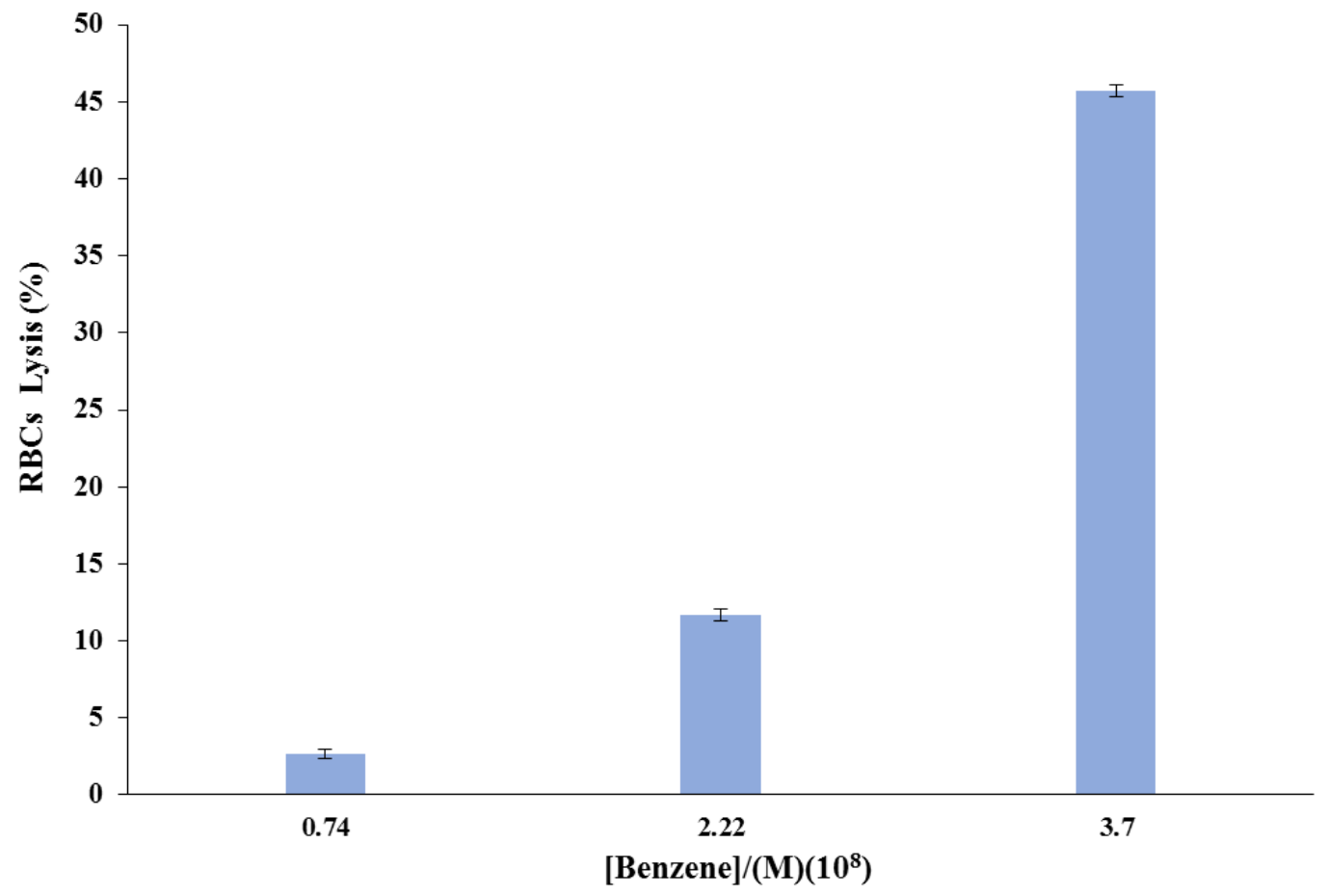

Fig. 1, Hemolytic effects (Hemolysis \%) of benzene on RBCs at various concentrations of benzene $\left(7.4 \times 10^{-9}-3.7 \times 10^{-8} \mathrm{M}\right)$ at incubation time of 45 min at $37^{\circ} \mathrm{C}$ and $\mathrm{pH}=7.4$.

\subsection{UV-Vis spectral changes in Hb-benzene interactions}

Fig. 2 shows the UV-Vis spectral deviation by increasing benzene concentration. Three regions on the normal hemoglobin spectrum can be considered. The first region is related to globin absorption at $285 \mathrm{~nm}$ related to tryptophan and tyrosine absorption in this wavelength. The second region is B or Soret band and is related to heme ironporphyrin complex absorption at $415 \mathrm{~nm}$. The third region is Q band and is related to the oxy- and deoxy-forms of heme at 550-600 nm. Fig. 2 shows that the B and Q bands exhibit hypochromicity with increasing benzene concentration while globin region showed hyperchromicity. Increasing in globin peak absorption is due to conformational changes and the interaction of benzene with aromatic chromophores of globin and increasing hydrophobicity around these chromophors which was accompanied with a red 
shift that is in agreement with increasing hydrophobicity. At higher concentration of benzene the globin band disturb that it is due to denaturation of globin section. Inset of Fig. 2 represents the concentration of various species of hemoglobin at various concentrations of benzene [36-38].

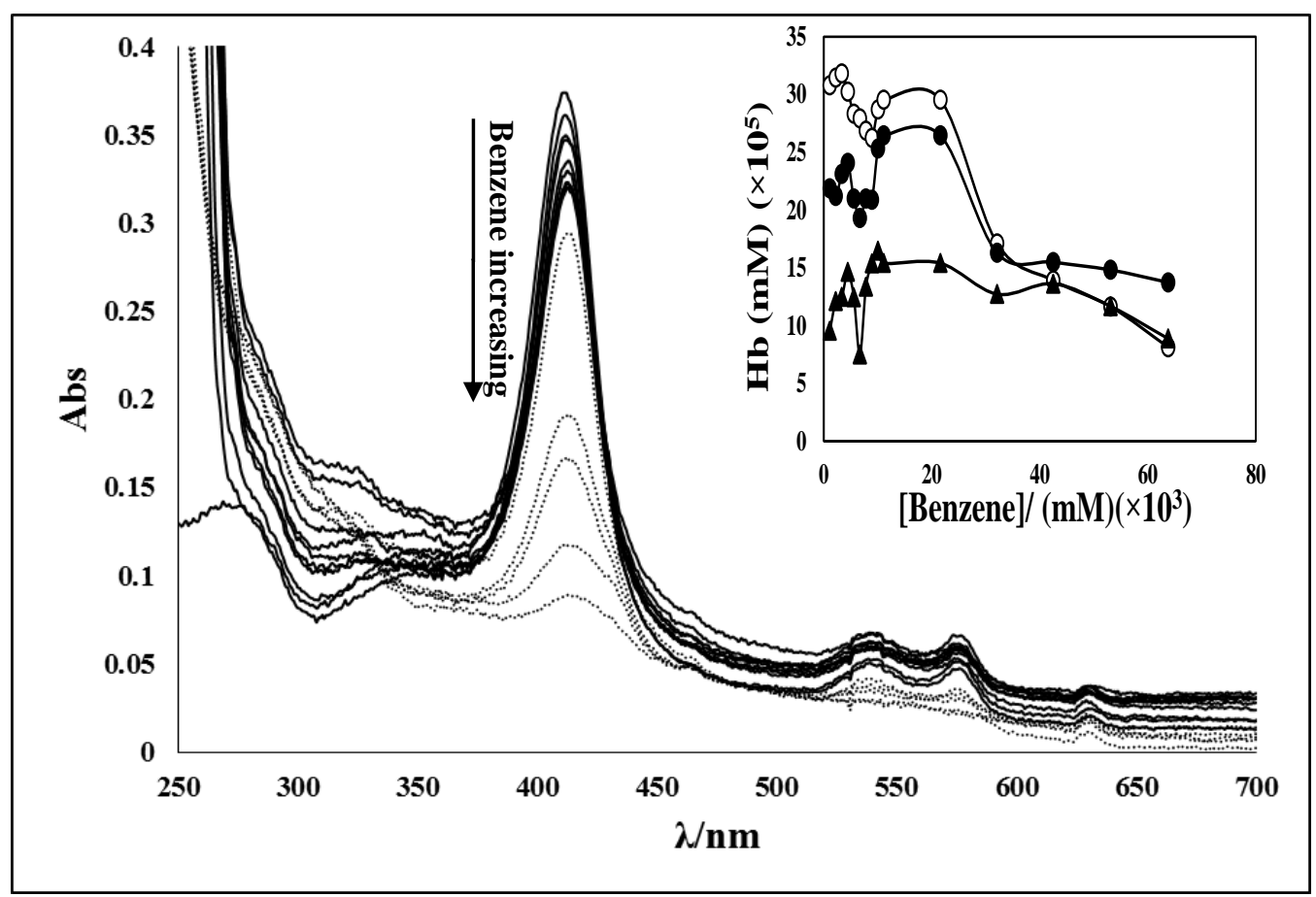

Fig. 2, UV-Vis spectra of hemoglobin in the presence of various concentrations of benzene $(0.70 \mu \mathrm{M})$ at incubation time of $30 \mathrm{~min}, \mathrm{pH}=7.4$ and $25^{\circ} \mathrm{C}$. Solid lines spectra (-) show decrease in absorbance in normal conditions and in the presence of oxygen. Effect of oxygen removing on benzene-Hb interaction was shown in dash line (.....). The inset represents the variation of hemoglobin species (oxy, deoxy, and met forms) at various concentrations of benzene; ( $\bigcirc$ : oxy form), ( $\bullet$ : deoxy form), ( $\mathbf{\Lambda}:$ met form).

The oxy form of hemoglobin was decreased, while the deoxy form increased slowly and then decreased, but the met form first increased and then decreased. Decreasing of the three forms of hemoglobin species concentration demonstrated that some heme groups were destructed by increasing benzene concentration which is in agreement with 
fluorescence heme degradation data. As we know the Soret band is characteristic band related to heme group of the hemoglobin and the changes in this band related to the benzene interaction with heme in the hydrophobic pocket of $\mathrm{Hb}$. The decrease in Soret band approved that the benzene penetrated to the porphyrin complex vicinity in the hydrophobic pocket and interacted with the complex using $\pi$ electrons of benzene ring with the iron center (see Fig.8 and docking data). A $5 \mathrm{~nm}$ red shift in Soret band was observed that demonstrate the increasing hydrophobicity around the inorganic complex chromophor. Hypochromicity effect in the Q band was related to the fact that benzene shows competitive effect on the oxy site of the heme. In oxy form, two peaks were clearly seen in these wavelengths that are approved for oxygen binding to heme. Increasing of benzene decreased these peaks due to competition of benzene with oxygen for the oxy sites on the heme. To provide further proof for this mechanism, we removed the oxygen from sample solution by purging pure nitrogen gas and then benzene added to the sample solution. According to the docking data, benzene interaction with hemoglobin at hydrophobic pocket and with heme group have lower binding free energy and as can be seen in figure 8 , benzene molecule being close to heme group at oxy site of heme. Also the results in figure 2 shows that, by removing of solution free oxygen the heme release the bonded oxygen and consequently benzene interact with deoxy-heme in this site better than the oxy form (see figure 2). According to these results, benzene interaction with deoxy form of hemoglobin is energetically suitable in comparison with other species and surprisingly this interaction was not reversible by re-purging oxygen in the experimental solution. 


\subsection{Hemoglobin aggregation potential with benzene}

Aggregation potential experiments were performed in the absence or presence of benzene at various concentrations. Fig. 3 shows that the aggregation potential of hemoglobin was increased by increasing benzene concentration. As mentioned previously, hydrophobic interactions have major roles in benzene interaction with hemoglobin, and caused the protein denaturation. The possibility of aggregation was increased by increasing hydrophobic surfaces on the hemoglobin and consequently benzene concentration.

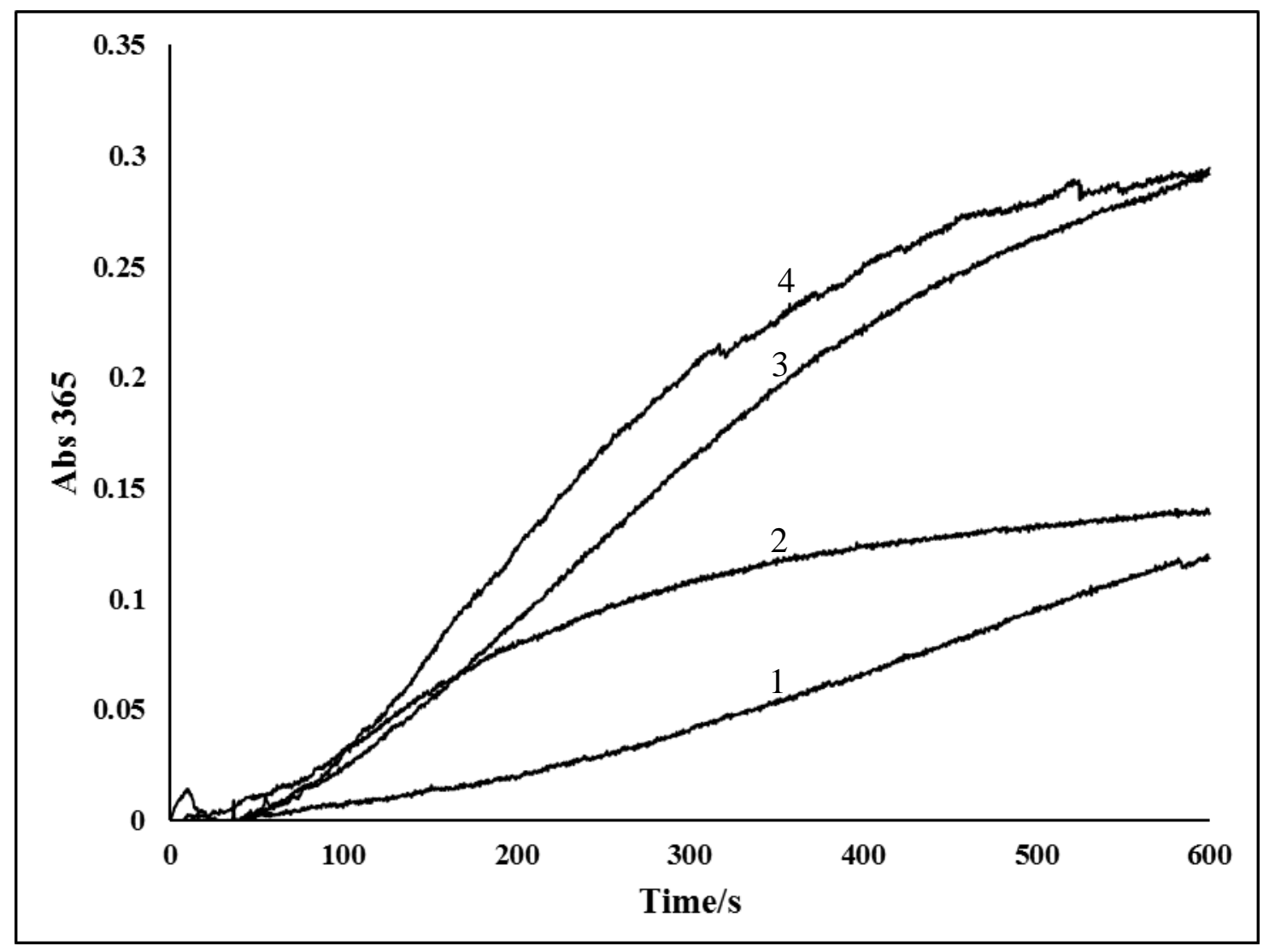

Fig. 3, Aggregation potential of hemoglobin in the presence of benzene ((1): without benzene; (2): $5.6 \times 10^{-9} \mathrm{M} ;(3): 2.8 \times 10^{-8} \mathrm{M}$; and (4): $5.6 \times 10^{-8} \mathrm{M}$ of benzene), at $\mathrm{pH}=7.4$. 


\subsection{Thermal denaturation in the presence of benzene}

Thermally induced protein unfolding was monitored in UV region based on constant temperature increasing ramp in the protein sample. Thermal denaturation curves were collected at a fixed wavelength of $280 \mathrm{~nm}$ (Fig. 4). This wavelength is the specific for studying various proteins stability and denaturation. Due to the presence of at least one of the three aromatic amino acids tryptophan, phenyl alanine and tyrosine, in various proteins structures as spectrophotometric chromophors, characterisitics of these amino acids in protein structure were considered as detector for structural changes in proteins. The maximum absorption wavelength for these amino acids is in near to $280 \mathrm{~nm}$. So the spectral changes at $280 \mathrm{~nm}$ represent the changes in the microenvironment of these chromophor. So by considering these changes, studying the stability and denaturation of proteins[39]. The melting temperature of protein, Tm (midpoint transition temperature), was calculated from thermal denaturation curves. Effect of benzene on the thermal stability of hemoglobin was considered at various concentrations of benzene. The stability of the protein was decreased and its Tm shifted to lower temperatures by increasing benzene concentration. Inset in Fig.4 shows the variation of Tm by increasing benzene concentration. We also designed differential scanning calorimetry experiments for examining the accuracy of spectroscopic Tm results. 


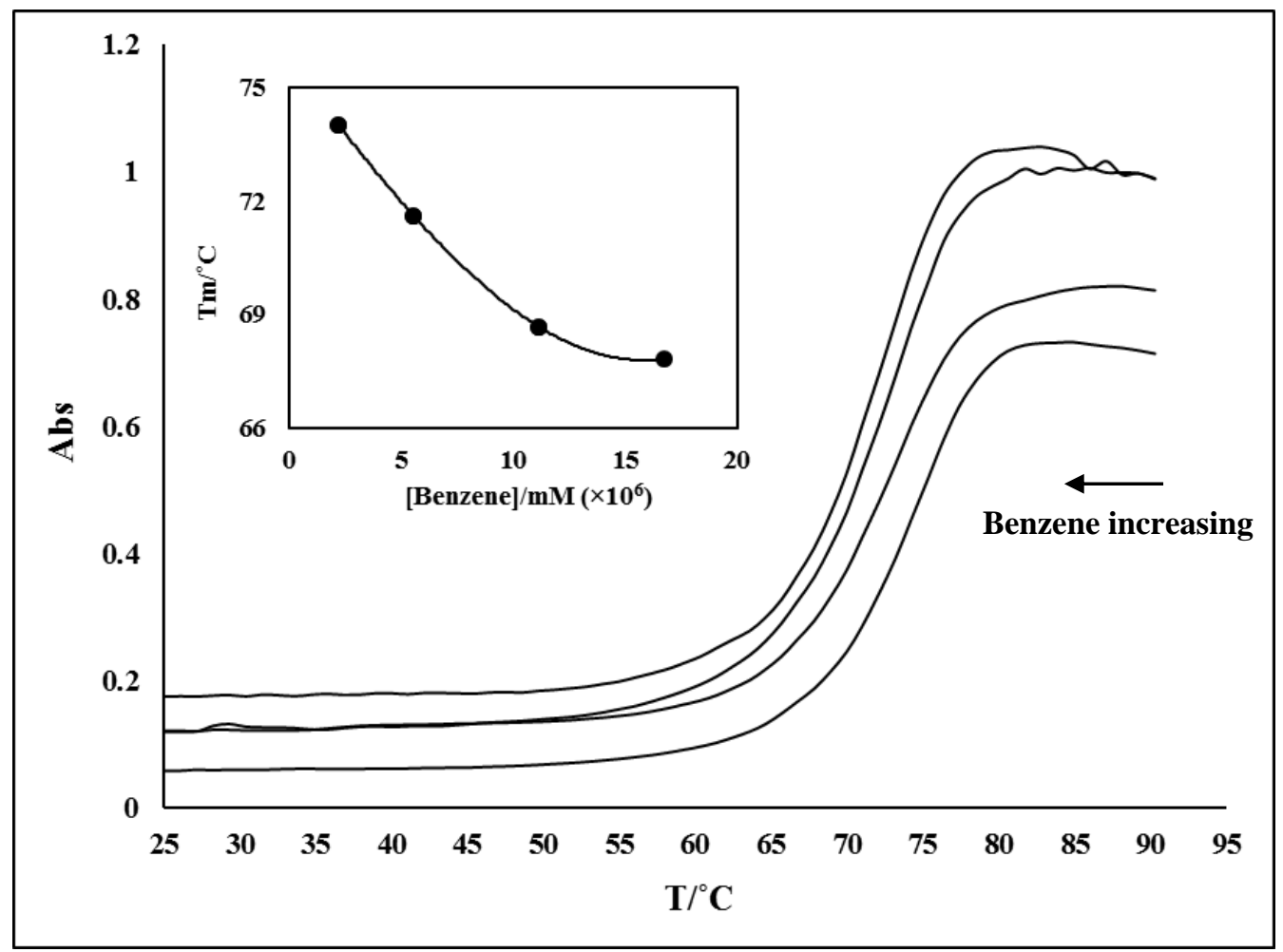

Fig. 4, Thermal denaturation profile of hemoglobin with increasing concentrations of benzene from 0 up to $2 \times 10^{-8} \mathrm{M}$, at $\mathrm{pH}=7.4$ and $280 \mathrm{~nm}$. The inset represents the variation of hemoglobin Tm against benzene concentration $\left(0-2 \times 10^{-8} \mathrm{M}\right)$ in experimental conditions.

Fig. 5 shows the DSC peaks for intact $\mathrm{Hb}$ and $\mathrm{Hb}$-benzene. The obtained $\mathrm{Tm}$ for intact $\mathrm{Hb}$ at experiment conditions was $75.9{ }^{\circ} \mathrm{C}$ that was comparable with thermal spectroscopic method $\left(\mathrm{Tm}_{\text {spect }}=74.2{ }^{\circ} \mathrm{C}\right)$. In the presence of benzene, Tm was decreased in both methods $\left(\operatorname{Tm} \operatorname{DsC}=72.9{ }^{\circ} \mathrm{C}\right.$ and $\left.\mathrm{Tm}_{\text {spect }}=71.6{ }^{\circ} \mathrm{C}\right)$. The relative concentration of protein/benzene was fixed in both experiments. 


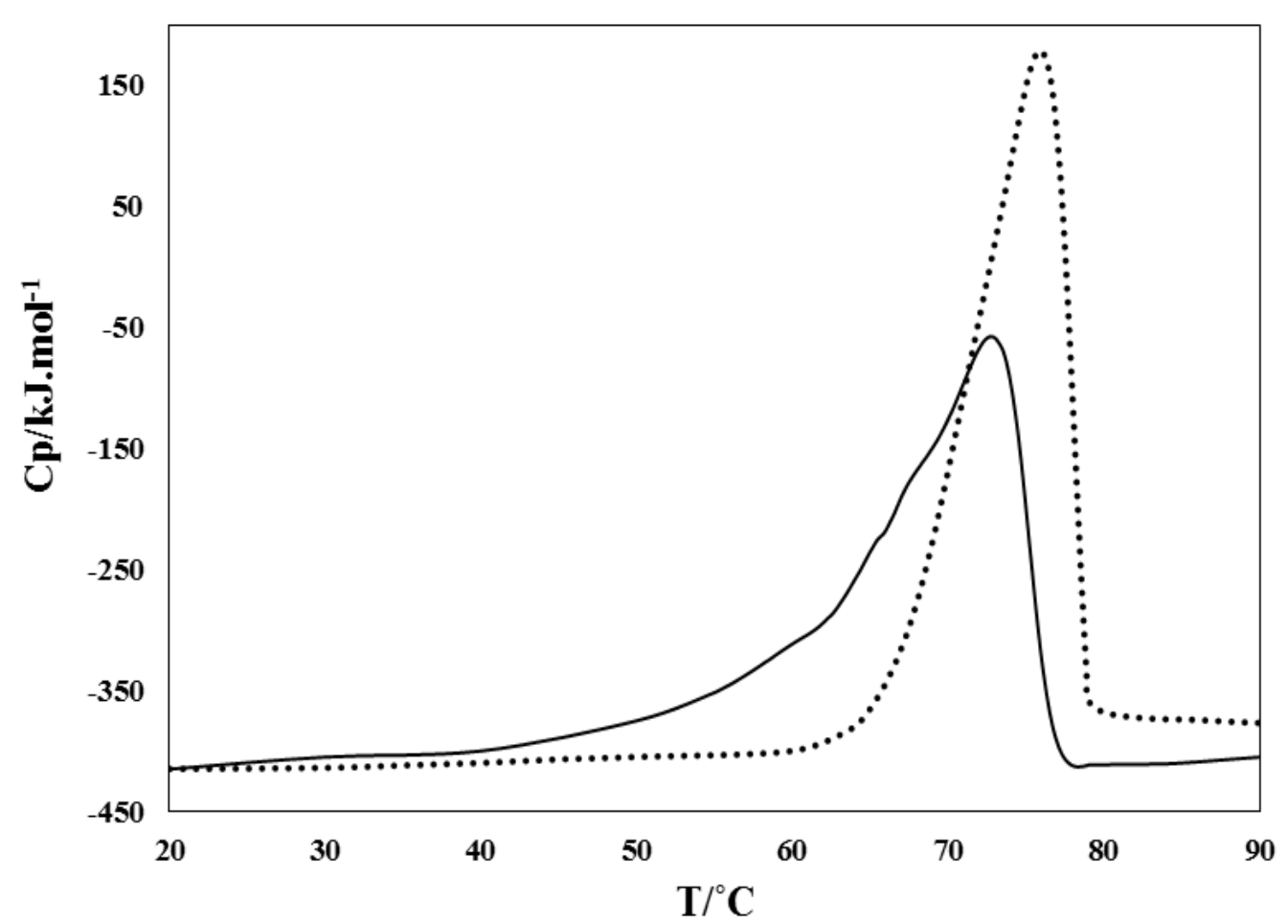

Fig. 5, Differential scanning calorimetric peaks related to pure hemoglobin and hemoglobin-benzene (hHb: $1 \mathrm{mg} / \mathrm{mL}$; [benzene]: $5.6 \times 10^{-8} \mathrm{M}$ )

\subsection{Fluorescence studies of heme degradation species}

The choice of optics in fluorescence detection and considering suitable analyte concentration are very important in fluorescence spectroscopic analysis. The fluorescence emission intensity of heme proteins varied depending on the concentration of these proteins in solution. Standard fluorescence instruments typically employ right-angle optics, wherein a highly absorptive sample, such as $\mathrm{Hb}$, introduces significant inner-filter effects at high concentrations due to the self-filtration and self-quenching effect but at lower concentrations, micro molar concentration, the inner filtration decreases and quenching effect is very low but in lower concentrations the peak intensity is low for analytical fluorescence measurements. In the other hand, the concentration of sample 
solution has dual effect on fluorescence emission intensity. It has been estimated that the hemes give rise to $~ 99 \%$ non-radiative quenching of the aromatic intrinsic fluorophores at high concentrations of protein [40]. As mentioned above heme act as quencher in this system and didn't have a fluorescence peak. Although hemes are not fluorescent compound, heme degradation can produce highly fluorescent degradation products[41]. According to the mentioned points in above, these spectral properties of hemoglobin give us the ability in detecting heme degradation products. Fluorescent emission spectra of heme degradation products were scanned from 330 to $550 \mathrm{~nm}$ at excitation wavelength of $321 \mathrm{~nm}$ and from 450 to $600 \mathrm{~nm}$ at excitation wavelength of $460 \mathrm{~nm}$, at $25^{\circ} \mathrm{C}$ (Fig. 6) as used previously by Nagababu and coworkers [41,42].

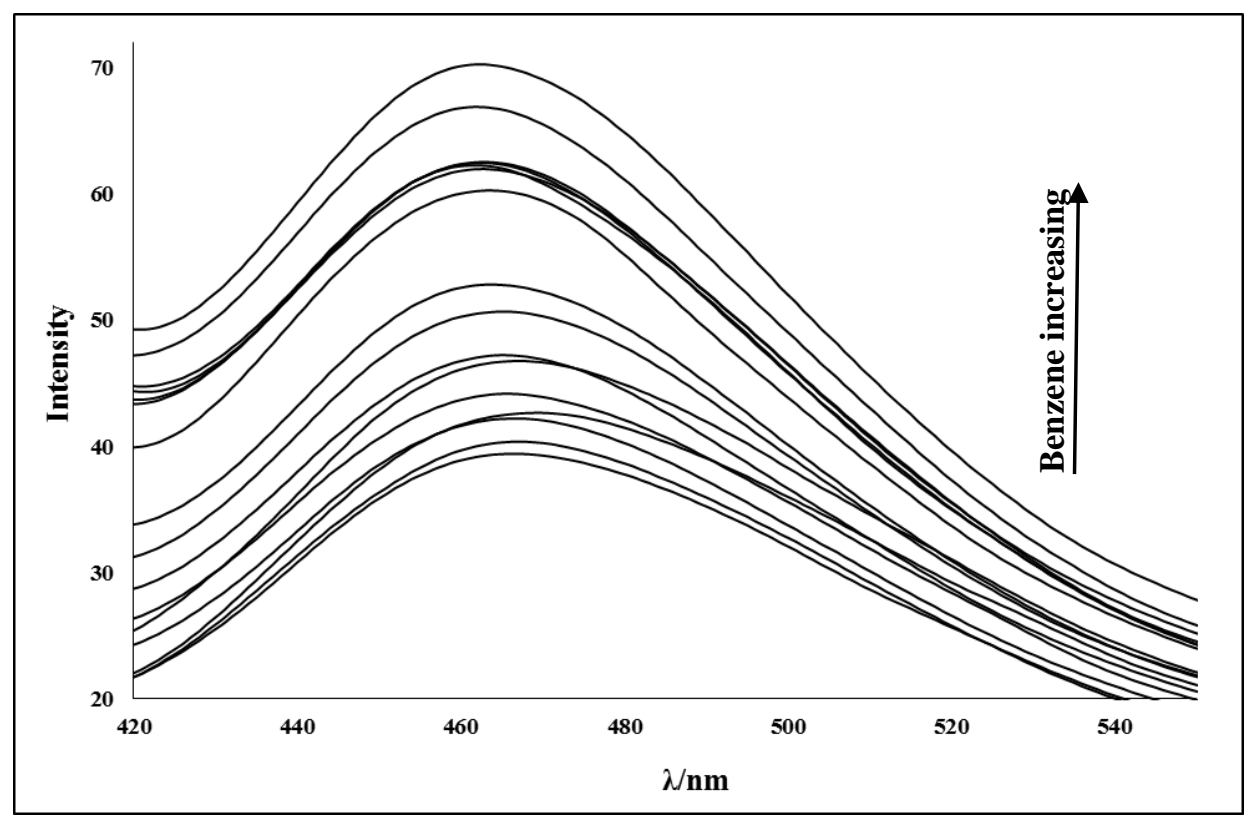

Fig. 6, Normal fluorescence spectra of heme degradation products recorded with increasing benzene concentration $\left(5 \times 10^{-9}-5 \times 10^{-8} \mathrm{M}\right)$ in the experimental solution of hemoglobin $(2 \mu \mathrm{M})$ at incubation time of $30 \mathrm{~min}, \mathrm{pH}=7.4$ and $25^{\circ} \mathrm{C}$.

From recorded fluorimeteric scans, it was clear that heme destruction materials induced in the presence of benzene. A widescreen peak appeared in the wavelength ranging from 
$330-550 \mathrm{~nm}$ (exited at $321 \mathrm{~nm}$ ), and from $450-600 \mathrm{~nm}$ (exited at $460 \mathrm{~nm}$ ), because of the production of some hemeo-porphyrin degradation products. The wide peak was a combination several peaks in this range, and separate peaks could not be obtained using conventional fluorescence spectroscopy alone.

\subsection{Synchronous fluorescence measurements}

Small quantities of the analyte can be detected directly using normal fluorescence spectroscopy. However, this technique is not suitable for the simultaneous and direct determination of multicomponent samples due to the spectral overlapping problems. Synchronous fluorescence spectroscopy (SFS) showed remarkable advantages, such as spectral simplification, bandwidth narrowing, reduced scattering interference and improved peak resolution. SFS provides an efficient tool to increase analytical selectivity, yet maintains the fluorimetric high sensitivity. Thus, SFS has become an attractive alternative for the simultaneous determination of multiple compound complex samples [43-45]. Constant-Wavelength Synchronous Fluorescence Spectroscopy (CWSFS) was used in this study. $\Delta \lambda=17 \mathrm{~nm}$ was considered for heme-destruction species and chemical micro-environment of tyrosine and tryptophan was seen in this CWSFS spectra (Fig. 7) [40]. 

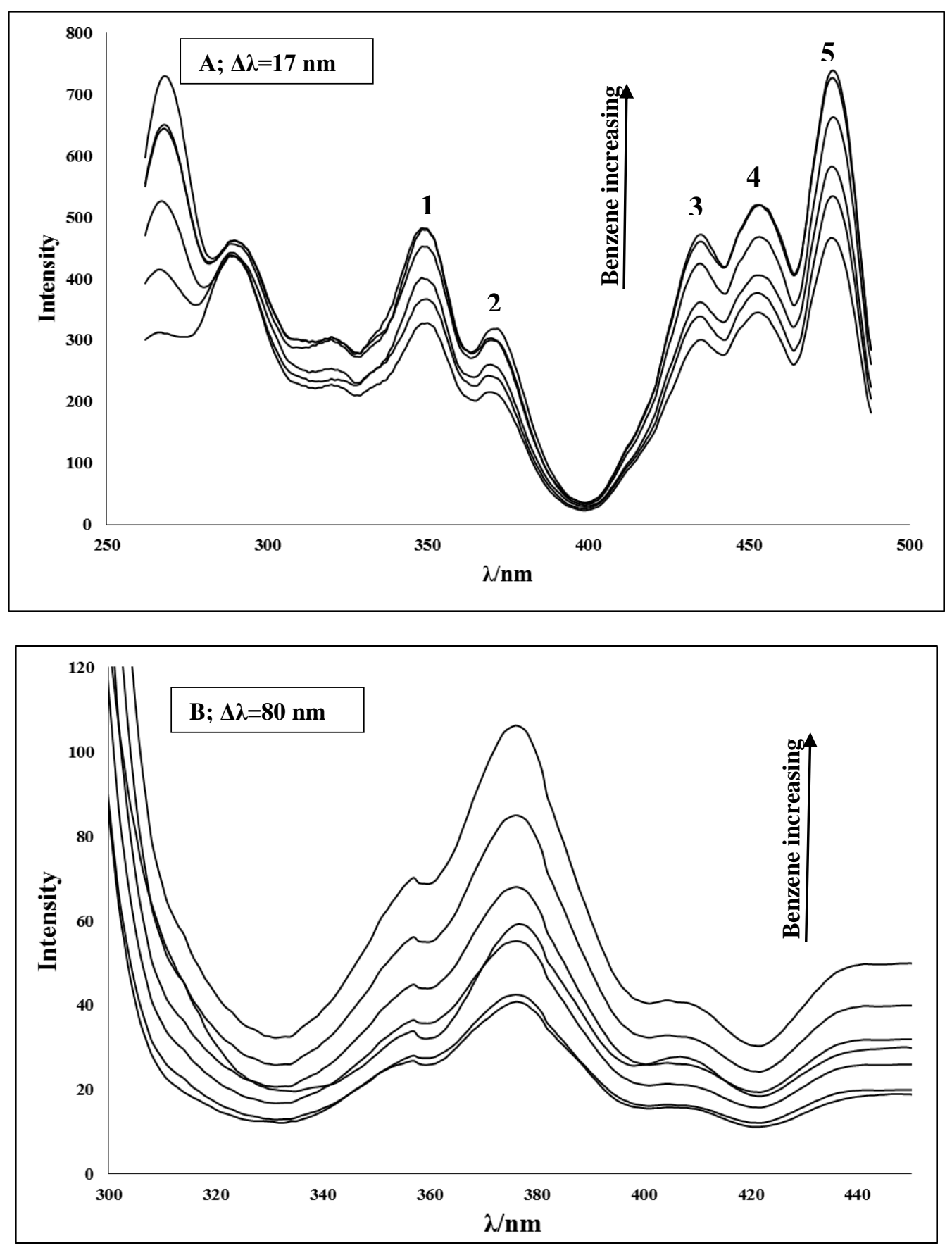

Fig. 7, Synchronous fluorescence spectra of hemoglobin recorded with increasing benzene concentration $\left(5 \times 10^{-9}-5 \times 10^{-8} \mathrm{M}\right)$ in the incubated sample solution (30 $\left.\mathrm{min}\right)$ by considering: (A: $\Delta \lambda=17 \mathrm{~nm}),(\mathrm{B}: \Delta \lambda=80 \mathrm{~nm})$, and slits was fixed at $10 \mathrm{~nm}$ at $\mathrm{pH}=7.4,25$ ${ }^{\circ} \mathrm{C}$.

In both spectra hyperchromicity was occurred by increasing of benzene concentration, but there was not any significant blue shift (2-3 nm). According to the obtained results, 
chemical micro-environment of both chromophors were changed slowly by increasing benzene concentration but the other peaks that related to heme destruction were well grown (Fig. 7(A)). The blue shift indicates increasing in hydrophobicity in microenvironment of flouro-chromophors that is in agreement with hydrophobic interactions of benzene and $\mathrm{Hb}$ in globin chains. In the other hands, it seems that benzene has great affinity to enter to the hydrophobic pocket of hemoglobin rather than to interact with globin chains. The molecular docking results were in agreement with obtained results, and showed that the benzene has high potential for the hydrophobic pocket of hemoglobin (see Fig. 8 and Table 1). As noted in previous sections, hemoglobin auto oxidation and redox function of oxy-hemoglobin can produce peroxide reagents. The peroxidase activity of hemoglobin increased in the oxidative stress and presence of chemical contaminants[11,25,41].

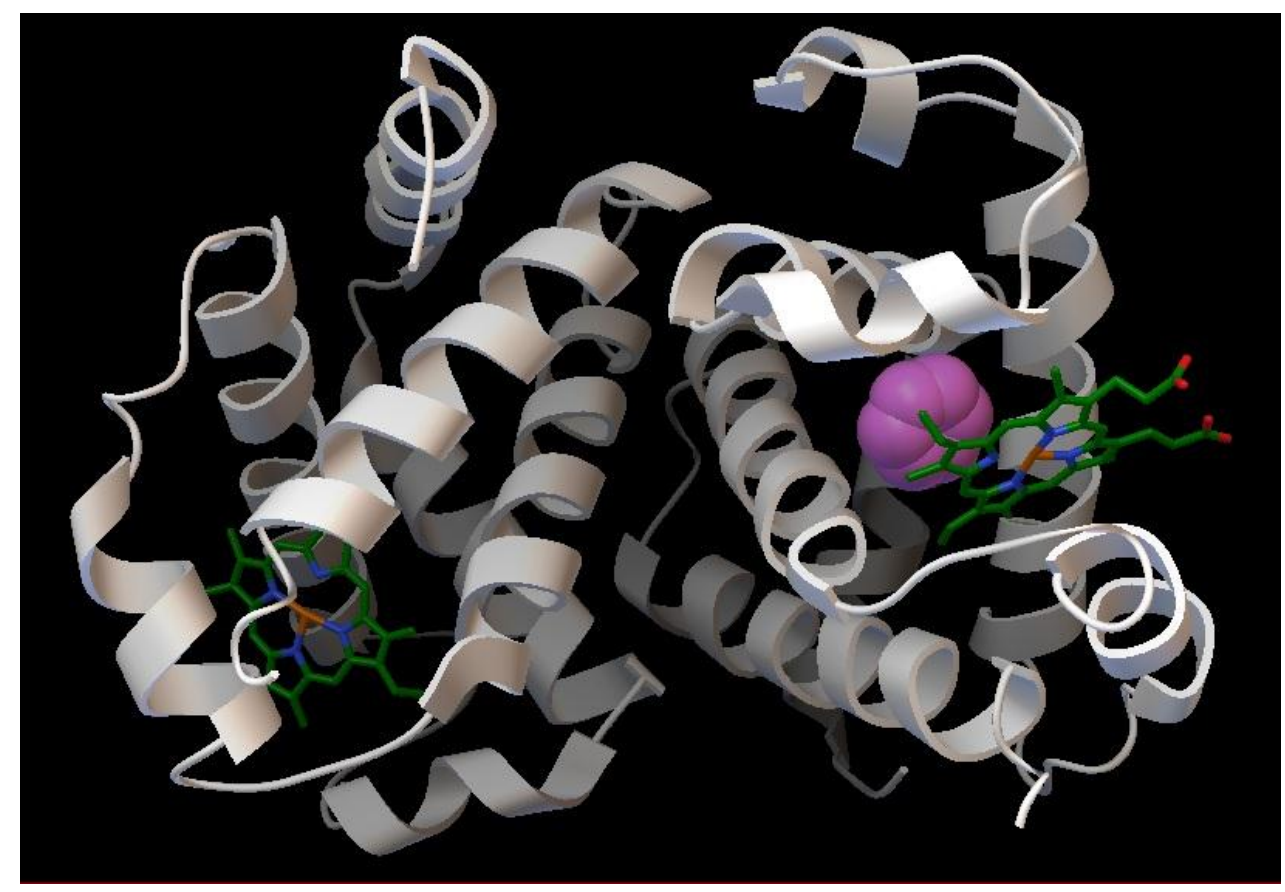

Fig. 8, Minimum energy MD conformation obtained from molecular docking simulation. The human hemoglobin and benzene are shown by ribbon structure and sphere model, respectively. 
Table 1, Energy of the binding complex obtained from molecular docking using AutoDock software (Units are in kcal/mol.).

\begin{tabular}{ccccc}
\hline Binding site & $\Delta \mathbf{G}^{\mathbf{a}}$ & $\Delta \mathbf{E}_{\mathbf{1}}{ }^{\mathbf{b}}$ & $\Delta \mathbf{E}_{\mathbf{3}}{ }^{\mathbf{c}}$ & Ligand efficiency \\
\hline Hydrophobic pocket & -4.03 & -4.03 & 0.00 & -0.67
\end{tabular}

${ }^{\mathrm{a}} \Delta \mathrm{G}$ is binding free energy change in the binding process, which is calculated in water solvent

${ }^{\mathrm{b}} \Delta \mathrm{E}_{1}$ is intermolecular interaction energy, which is a sum of Van der Waals energy, hydrogen binding energy, desolvation free energy and electrostatic energy.

${ }^{c} \Delta \mathrm{E}_{3}$ is electrostatic energy.

Non-enzymatic heme degradation initiated when the heme iron undergoes redox reactions. In the other hands, in the presence of oxygen, oxy hemoglobin produce peroxides that can be interacted with organic pollutants and induces various reactive oxygen species. Also met-hemoglobin interacts with benzene to oxidase the benzene to benzene oxide known as carcinogenic metabolite of benzene. In enzymatic heme degradation, heme oxidase specifically attacks the $\alpha$-methane bridge, but in nonenzymatic heme degradation reactive oxygen species randomly attack all the carbon methane bridges of the tetrapyrrole rings, producing various pyrrole products. According to the figure $7(\mathrm{~A}), 5$ species were detectable in benzene induced heme-destruction of hemoglobin. For identification and characterization of heme destruction species need to sensitive LC/Mass/Mass techniques that proposed to be consider for further studies in future. We can divide the SFS spectral region for various aromatic compounds as Table 2. According to the mentioned classification in the table 2 , the number of rings in resulted fluorophore from heme degradation can be estimated. Regard to the benzene SFS spectra (below $300 \mathrm{~nm}$ ), the benzene don't have spectral interference on other spectrum. 
Table 2, Data chart for synchronous spectra of poly aromatic hydrocarbons[46,47]

\begin{tabular}{c|c}
\hline Number of rings & Wavelength/nm \\
\hline 1 & below 280 \\
\hline 2 & $290-330$ \\
\hline 3 & $340-400$ \\
\hline 4 & $380-500$ \\
\hline
\end{tabular}

\subsection{Effect of benzene on oxygen affinity of $\mathrm{Hb}$}

Figure 9 represents the variation of oxygen saturation percentage versus sodium dithionite concentration. The midpoint of saturation graph was considered for comparison of oxygen affinity of hemoglobin. This point is practically equivalent to the $\mathrm{P}_{50}$ in oxygen dissociation curve of $\mathrm{Hb}$ [48]. According to the results in the presence of benzene $\mathrm{Hb}$ oxygen affinity plot shows big shift to the left and low dithionite concentrations. In other words, midpoint shifted, which demonstrated lowering oxygen affinity of hemoglobin in the presence of benzene. The increasing in the hydrophobic properties of these heme pocket of $\mathrm{Hb}$ are mainly responsible for these effects [49]. Also it can be seen that the sigmoidal shape of the oxygen affinity plot is removed and the first part of the plot don't have regular variation, which demonstrated destroying cooperative function and oxygen affinity of $\mathrm{Hb}$. 


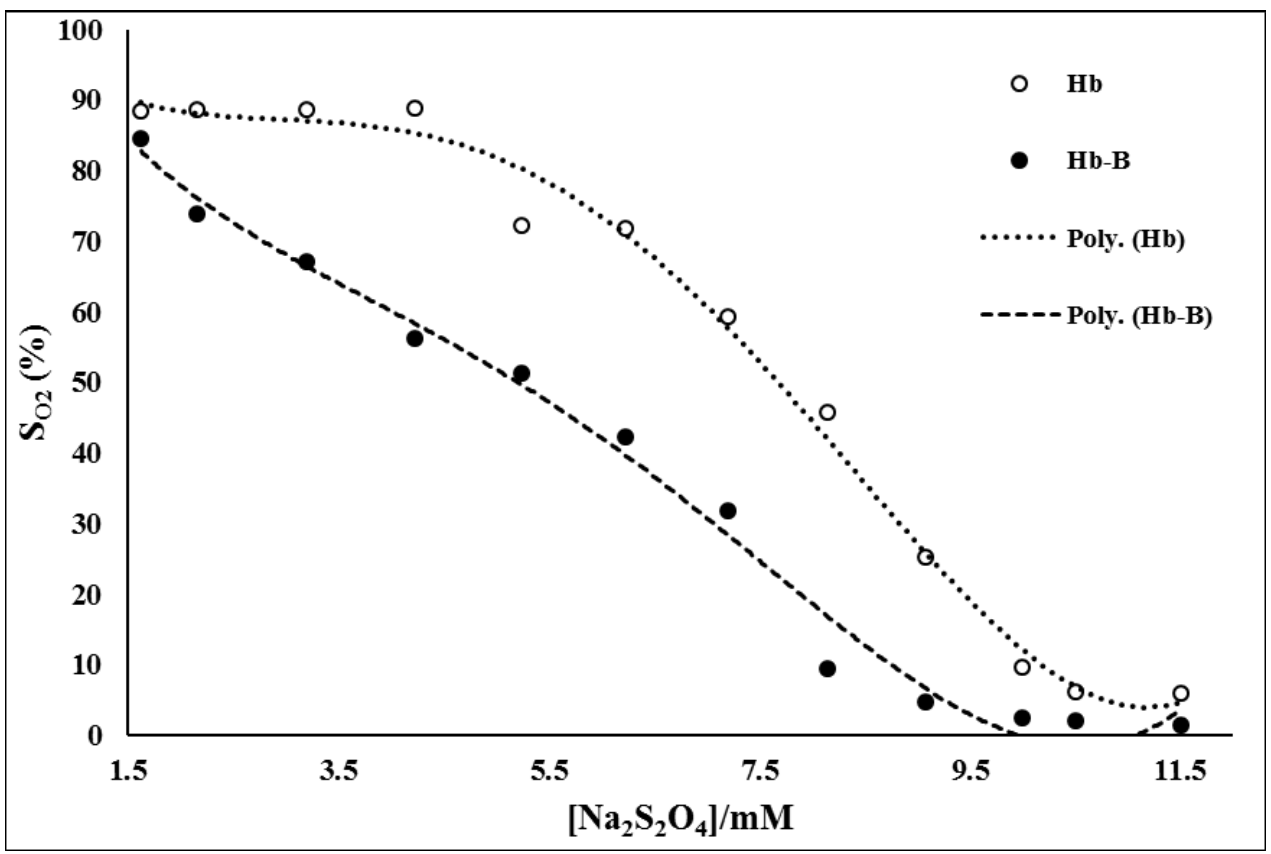

Fig. 9, Dithionite titration curve and saturation plot for Hemoglobin in the absence $(0)$ and presence $(\bullet)$ of benzene $\left(2.8 \times 10^{-8} \mathrm{M}\right)$ at $25^{\circ} \mathrm{C}$ and $\mathrm{pH}=7.4$.

According to the figure 10, the obtained results from the second procedure is in agreement with other results and shows great decreases in bonded oxygen to hemoglobin in the presence of benzene. Decreasing in molar concentration of bonded oxygen by increasing of total oxygen in sample solution indicated that oxygen affinity of hemoglobin greatly decreased and falls down the plot of oxygen affinity. 


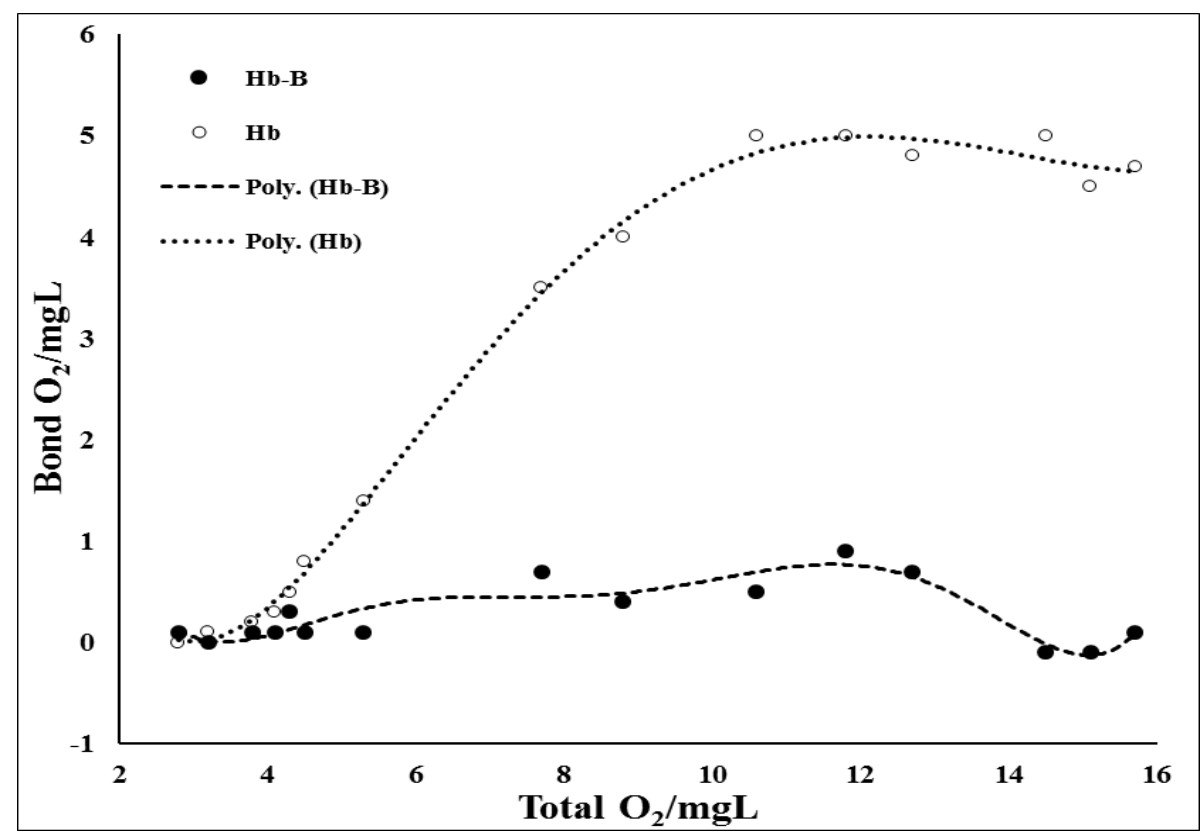

Fig. 10, The plot of bonded oxygen against total solved oxygen for hemoglobin in the absence $(\circ)$ and presence $(\bullet)$ of benzene $\left(2.8 \times 10^{-8} \mathrm{M}\right)$ at $25^{\circ} \mathrm{C}, \mathrm{pH}=7.4$ and $30 \mathrm{~min}$ incubation time.

\section{Conclusion}

The effect of benzene on hemoglobin structure, stability and heme destruction effect was considered. Benzene potential on hemolysing of RBCs was determined. According to the obtained results benzene affected the hemoglobin in both globin and prosthetic group parts of the macromolecule, but the affinity of benzene to enter to hydrophobic pocket was higher than globin interaction. By entering of benzene, heme excluding did not occurred and benzene showed competitive potential for oxy site on heme group. These results were in agreement with molecular docking and CWSFS results. The consequence of heme destruction effect induced at least 5 species. The obtained results confirmed that oxygen has structural stability effect on the macromolecule, and by removing of oxygen from oxy site of heme benzene can reach the oxy site and make interaction with heme groups. Purging of nitrogen for removing of 
benzene for returning to oxy hemoglobin showed irreversibility of the phenomena, and perhaps as a result of the destruction of heme groups. Benzene is classified in group 1of carcinogens and occupational studies in adults have demonstrated increased incidence of several types of leukemia in exposed humans. In 1948, the American Petroleum Institute (API) stated that "it is generally considered that the only absolutely safe concentration for benzene is zero" (American Petroleum Institute, API Toxicological Review, Benzene, September 1948). According to obtained results of the current study, it is clear that benzene can alter RBCs and hemoglobin at low concentrations affecting both structural and functional properties of hemoglobin.

\section{Acknowledgements}

The support of University of Tehran, Center of Excellence in Biothermodynamics

(CEBiotherm), Iran National Science Foundation (INSF), Iran National Elites Foundation (INEF), Office of Health, Safety and Environment (HSE) Oil Ministry, Iran and UNESCO Chair on Interdisciplinary Research in Diabetes (University of Tehran, Tehran, Iran), Iran Society of Biophysical Chemistry is gratefully acknowledged. 


\section{References}

[1] L.S. Costanzo, Physiology, Lippincott Williams \& Wilkins, 2007.

[2] A. Maton, Human Biology and Health: I, Pearson Prentice Hall, 1993.

[3] R. Liddington, Z. Derewenda, E. Dodson, R. Hubbard, G. Dodson, High resolution crystal structures and comparisons of T-state deoxyhaemoglobin and two liganded T-State haemoglobins: T( $\alpha$-oxy)haemoglobin and T(met)haemoglobin, J. Mol. Biol. 228 (1992) 551-579.

[4] M.F. Perutz, Stereochemistry of Cooperative Effects in Haemoglobin: HaemHaem Interaction and the Problem of Allostery, Nature. 228 (1970) 726-734.

[5] B. Shaanan, The iron-oxygen bond in human oxyhaemoglobin, Nature. 296 (1982) 683-684.

[6] Y.-Q. Wang, H.-M. Zhang, G.-C. Zhang, S.-X. Liu, Q.-H. Zhou, Z.-H. Fei, et al., Studies of the interaction between paraquat and bovine hemoglobin, Int. J. Biol. Macromol. 41 (2007) 243-250.

[7] K.M.O. Bruce D. Sidell, When bad things happen to good fish: the loss of hemoglobin and myoglobin expression in Antarctic icefishes, J. Exp. Biol. 209 (2006) 1791-1802.

[8] Jon V. Dacie, The Hemoltyic Anemias, Congenital and Acquired, Grune and Stratton, New York, USA, 1967.

[9] M.H. Steinberg, Disorders of Hemoglobin: Genetics, Pathophysiology, and Clinical Management, Cambridge University Press, 2001.

[10] M.J. Percy, N. V McFerran, T.R.J. Lappin, Disorders of oxidised haemoglobin, Blood Rev. 19 (2005) 61-68.

[11] E. Nagababu, J.M. Rifkind, Heme degradation by reactive oxygen species., Antioxid. Redox Signal. 6 (2004) 967-78. 
[12] E. Valero, M.-I. González-Sánchez, M.-T. Pérez-Prior, Removal of Organic Pollutants from Industrial Wastewater by Treatment with Oxidoreductase Enzymes, in: Handb. Environ. Chem., Springer Berlin Heidelberg, 2014: pp. 1-23.

[13] Roy J. Irwin, environmental contaminants encyclopedia entry for BTEX and BTEX compounds, Environ. Contam. Encycl. (1997) 125-137.

[14] H.J. Martin, S. Riazanskaia, C.L.P. Thomas, Sampling and characterisation of volatile organic compound profiles in human saliva using a polydimethylsiloxane coupon placed within the oral cavity, Analyst. 137 (2012) 3627-3634.

[15] P. Mochalski, J. King, M. Klieber, K. Unterkofler, H. Hinterhuber, M. Baumann, et al., Blood and breath levels of selected volatile organic compounds in healthy volunteers, Analyst. 138 (2013) 2134-2145.

[16] T.S. do Nascimento, R.O.L. Pereira, H.L.D. de Mello, J. Costa, Metemoglobinemia: do diagnÃltextthreesuperiorstico ao tratamento, Rev. Bras. Anestesiol. 58 (2008) 651-664.

[17] D. Arnold, C. Plank, E. Erickson, F. Pike, Solubility of Benzene in Water., Ind. Eng. Chem. Chem. Eng. Data Ser. 3 (1958) 253-256. doi:10.1021/i460004a016.

[18] R.H. Lindsey, R.P. Bender, N. Osheroff, Effects of Benzene Metabolites on DNA Cleavage Mediated by Human Topoisomerase II $\alpha$ : 1,4-Hydroquinone Is a Topoisomerase II Poison, Chem. Res. Toxicol. 18 (2005) 761-770.

[19] A.B. Lindstrom, K. Yeowell-O'Connell, S. Waidyanatha, T.A. McDonald, B.T. Golding, S.M. Rappaport, Formation of Hemoglobin and Albumin Adducts of Benzene Oxide in Mouse, Rat, and Human Blood, Chem. Res. Toxicol. 11 (1998) 302-310.

[20] L. Wang, X. He, Y. Bi, Q. Ma, Stem Cell and Benzene-Induced Malignancy and Hematotoxicity, Chem. Res. Toxicol. 25 (2012) 1303-1315.

[21] K.-M. Chen, K. El-Bayoumy, J. Cunningham, C. Aliaga, H. Li, A.A. Melikian, Detection of Nitrated Benzene Metabolites in Bone Marrow of B6C3F1 Mice Treated with Benzene, Chem. Res. Toxicol. 17 (2004) 370-377.

[22] R. Hosseinzadeh, A.A. Moosavi-Movahedi, H. Ghourchian, Electrochemistry and 
molecular modeling of the hemoglobin-benzene interaction with a nanocrystalline mixed metal oxide, RSC Adv. 4 (2014) 49128-49136. doi:10.1039/C4RA08018A.

[23] R. Hosseinzadeh, A.A. Moosavi Movahedi, H. Ghourchian, New insight on biological interaction analysis: new nanocrystalline mixed metal oxide SPME fiber for GC-FID analysis of BTEX and its application in human hemoglobin-benzene interaction studies., PLoS One. 9 (2008) 308-318. doi:10.1371/journal.pone.0102992.

[24] A. Riggs, Preparation of blood hemoglobins of vertebrates, in: E.C. Eraldo Antonini Luigi Rossi-Bernardi (Ed.), Hemoglobins, Academic Press, 1981: pp. 529.

[25] N. Salehi, A.A. Moosavi-Movahedi, L. Fotouhi, S. Yousefinejad, M. Shourian, R. Hosseinzadeh, et al., Heme degradation upon production of endogenous hydrogen peroxide via interaction of hemoglobin with sodium dodecyl sulfate, J. Photochem. Photobiol. B Biol. 133 (2014) 11-17.

[26] I. Ali, I. Naseem, Hemolysis of human red blood cells by combination of riboflavin and aminophylline, Life Sci. 70 (2002) 2013-2022.

[27] A. Chakrabarti, D. Bhattacharya, S. Deb, M. Chakraborty, Differential thermal stability and oxidative vulnerability of the hemoglobin variants, $\mathrm{HbA} 2$ and $\mathrm{HbE}$., PLoS One. 8 (2013) e81820.

[28] J.N. Miller, Recent developments in fluorescence and chemiluminescence analysis. Plenary lecture, Analyst. 109 (1984) 191-198.

[29] G.M. Morris, H. Ruth, W. Lindstrom, M.F. Sanner, R.K. Belew, D.S. Goodsell, et al., Software news and updates AutoDock4 and AutoDockTools4: Automated docking with selective receptor flexibility, J. Comput. Chem. 30 (2009) 27852791. doi:10.1002/jcc.21256.

[30] D. W. L., PyMOL: an open-source molecular graphics tool, Ccp4 Newslett Protein Crystallogr. 40 (2002) 11-16.

[31] B.D. Tietz, N. W. \& Andresen, Textbook of clinical chemistry, 3rd ed., Philadelphia: WB Saunders Co., Philadelphia, 1986. 
[32] T.-O.K. Bogadi-Are Ana, Turk Rajka, Karacic Visnja, Zavalic Marija, Red Blood Cell Glycerol Lysis and Hematologic Effects in Occupational Benzene Exposure, Toxicol. Ind. Health. 13 (1997) 485-494.

[33] Ponder Eric, Acceleration of Haemolysis in Relation to Chemical Structure: I. Benzene Derivatives, J. Exp. Biol. 16 (1939) 38-48.

[34] H.M.T. Al-Assadi, A.J. Baillie, A.T. Florence, The hemolytic activity of non-ionic surfactants, J. Pharm. Pharmacol. 42 (1990) 161P-161P.

[35] M.P. Vinardell, M.R. Infante, The relationship between the chain length of nonionic surfactants and their hemolytic action on human erythrocytes, Comp. Biochem. Physiol. Part C Pharmacol. Toxicol. Endocrinol. 124 (1999) 117-120.

[36] S.S. Dayer Mohammad Reza, Moosavi-Movahedi Ali Akbar, Norouzi Parviz, Ghourchian, Hedayat-Olah, Inhibition of Human Hemoglobin Autoxidation by Sodium n-Dodecyl Sulphate, J. Biochem. Mol. Biol. 35 (2002) 364-370.

[37] R.E. Benesch, R. Benesch, S. Yung, Equations for the spectrophotometric analysis of hemoglobin mixtures, Anal. Biochem. 55 (1973) 245-248.

[38] M. Mojtahedi, H. Parastar, M. Jalali-Heravi, J. Chamani, F.C. Chilaka, A.A. Moosavi-Movahedi, Comparison between two different hemichromes of hemoglobins ( $\mathrm{HbA}$ and $\mathrm{HbS}$ ) induced by n-dodecyl trimethylammonium bromide: Chemometric study, Colloids Surfaces B Biointerfaces. 63 (2008) 183-191.

[39] C.N. Pace, Measuring and increasing protein stability, Trends Biotechnol. 8 (1990) 93-98.

[40] R. Hirstch, Hemoglobin Fluorescence, in: R. Nagel (Ed.), Hemoglobin Disord. SE - 9, Humana Press, 2003: pp. 133-154. doi:10.1385/1-59259-373-9:133.

[41] E. Nagababu, J.M. Rifkind, Heme Degradation during Autoxidation of Oxyhemoglobin, Biochem. Biophys. Res. Commun. 273 (2000) 839-845.

[42] E. Nagababu, J.M. Rifkind, Formation of Fluorescent Heme Degradation Products during the Oxidation of Hemoglobin by Hydrogen Peroxide, Biochem. Biophys. Res. Commun. 247 (1998) 592-596. 
[43] L.Y. He Lifang, Lin Danli, Application and Development of Synchronous Fluorescence Spectrometry, Prog. Chem. 16 (n.d.) 879.

[44] Y.-Q. Li, X.-Y. Li, A. Shindi, Z.-X. Zou, Q. Liu, L.-R. Lin, et al., Synchronous Fluorescence Spectroscopy and Its Applications in Clinical Analysis and Food Safety Evaluation, Springer New York, 2012.

[45] D.Y. Pharr, J.K. McKenzie, A.B. Hickman, Fingerprinting Petroleum Contamination Using Synchronous Scanning Fluorescence Spectroscopy, Ground Water. 30 (1992) 484-489.

[46] T.V. Dinh, Multicomponent analysis by synchronous luminescence spectrometry, Anal. Chem. 50 (1978) 396-401.

[47] S.G. Wakeham, Synchronous fluorescence spectroscopy and its application to indigenous and petroleum-derived hydrocarbons in lacustrine sediments, Environ. Sci. Technol. 11 (1977) 272-276.

[48] A.L. Lehninger, D.L. Nelson, M.M. Cox, Lehninger Principles of Biochemistry, W. H. Freeman, 2005.

[49] S. Ariaeenejad, M. Habibi-Rezaei, S. Jamili, M. Fatemi, N. Poursasan, F. Ahmad, et al., Biochemical Characterization of Hemoglobins from Caspian Sea Sturgeons (Acipenser persicus and Acipenser stellatus), Cell Biochem. Biophys. 62 (2012) 73-81. 
Graphical Abstract
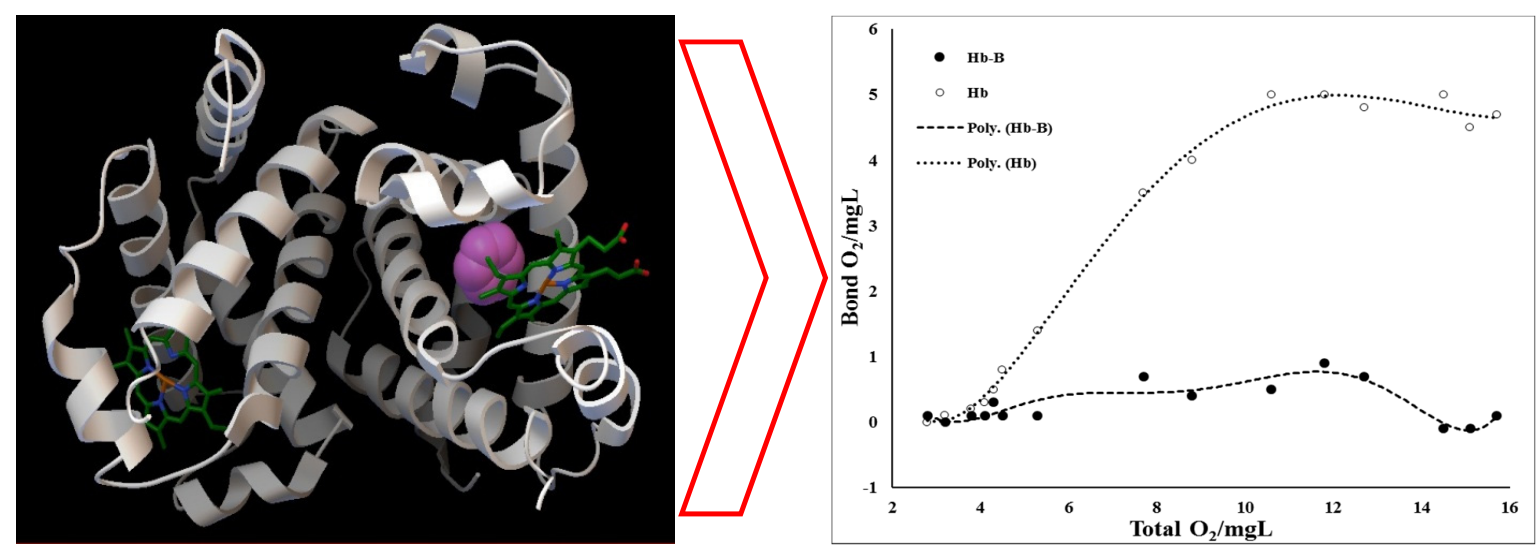